\title{
Retraction Note to: Physiological Role of Gamma Aminobutyric Acid (GABA) in Salt Stress Tolerance
}

\author{
Syed Uzma Jalil and Mohammad Israil Ansari
}

\author{
Retraction Note to: \\ Chapter "Physiological Role of Gamma Aminobutyric Acid \\ (GABA) in Salt Stress Tolerance" in: Hasanuzzaman M. (eds), \\ Plant Ecophysiology and Adaptation under Climate \\ Change: Mechanisms and Perspectives II, \\ https://doi.org/10.1007/978-981-15-2172-0_13
}

The authors have retracted this chapter (Jali and Ansari, 2020a) because it has been previously published in another book (Jali and Ansari, 2020b). [All authors agree with this retraction]

1. Jalil S.U., Ansari M.I. (2020a) Physiological Role of Gamma Aminobutyric Acid (GABA) in Salt Stress Tolerance. In: Hasanuzzaman M. (eds) Plant Ecophysiology and Adaptation under Climate Change: Mechanisms and Perspectives II. Springer, Singapore

2. Jalil S.U., Ansari M.I. (2020b) Physiological Role of Gamma-Aminobutyric Acid in Salt Stress Tolerance. In: Hasanuzzaman M., Tanveer M. (eds) Salt and Drought Stress Tolerance in Plants. Signaling and Communication in Plants. Springer, Cham 